УДК 82I.I6I.I.0

ББК $83.3(2 \mathrm{Poc}=\mathrm{Pyc}) 52$

\section{ОБРАЗ ЗЕМЛИ И ЕГО ФУНКЦИИ В РОМАНЕ Л.Н. ТОЛСТОГО «ВОСКРЕСЕНИЕ»}

Исследование выполнено при финансовой поддержке РФФИ в рамках научного проекта № 20-ОІ2-оОІо2

Аннотация: В работе доказывается, что ситуация катастрофы в масштабах страны, изображенная Л.Н. Толстым в романе-эпопее «Война и мир», была использована им и при представлении относительно мирного времени в романе «Воскресение»: Толстой поднимает вопрос нарастания в России страшного кризиса, проблему выживания народа. Важнейшая функция образа земли, одного из центральных в романе, заключается в поддержании стройной системы толстовских антитез, направленных в поздний период творчества писателя не только на обличение власти и существующих порядков, но и на создание масштабного образа национального единства. Образ земли в «Воскресении» организует тематические и идейные пласты, связанные с реализацией эпопейных признаков. Автор статьи доказывает, что решение писателя отказаться от остросоциального и политического земельного вопроса как центра произведения, присутствовавшее в черновых материалах, на самом деле не было полностью воплощено. В итоговом тексте образ земли несколько скрывается за изображением тяжести жизни заключенных и попыток помощи им, предпринимаемых Нехлюдовым. Однако он теснейшим образом связан со всеми сферами русской жизни, является показателем духовного роста Нехлюдова, позволяет вписать воскресение героя не просто в конкретные реалии исторического времени, но представить его в традициях христианской антропологии. Образ земли придает роману надэпохальный, трансисторический смысл, способствует реализации в произведении религиозного сознания.

ключевые слова: Толстой, эпический роман, эпопея, образ земли, земельный вопрос, государство, этапы духовного роста, христианская антропология.

Информация об авторе: Валерия Геннадьевна Андреева - доктор филологических наук, ведущий научный сотрудник, Институт мировой литературы им. А.М. Горького Российской академии наук, ул. Поварская, д. 25 а, І2Іо69 г. Москва, Россия; профессор кафедры Отечественной филологии, Костромской государственный университет, ул. Дзержинского, д. I7, I56005 г. Кострома, Россия. ORCID ID: https://orcid.org/oooo-0002-4558-3153

E-mail: lanfra87@mail.ru

Для цитирования: Андреева В.Г. Образ земли и его функции в романе Л.Н. Толстого «Воскресение» // Studia Litterarum. 2020. Т. 5, № 3. С. 236-25I. DOI: https://doi.org/I0.22455/2500-4247-2020-5-3-236-25I 


\title{
THE IMAGE OF THE LAND AND ITS FUNCTIONS IN TOLSTOY'S NOVEL RESURRECTION
}

This is an open access article

distributed under the Creative Commons Attribution 4.0 International (CC BY 4.0)

\author{
(C) 2020. V.G. Andreeva \\ A.M. Gorky Institute of World Literature \\ of the Russian Academy of Sciences, Moscow, Russia; \\ Kostroma State University, Kostroma, Russia \\ Received: April 24, 2020 \\ Date of publication: September 25, 2020
}

Acknowledgements: The study was supported by the Russian Fund for Basic Research, project number 20-OI2-00IO2.

Abstract: The paper argues that Leo Tolstoy uses the national disaster paradigm represented in the epic novel War and Peace to depict the relatively peaceful time in his novel Resurrection as he raises the question of the growing crisis in Russia and the problem of the survival of Russian people. One of the central images of this latter novel is the image of the land. Its function is to support a system of Tolstoy's antitheses that in his late period, aimed not only to rebuke the existing order but also to create a large-scale image of national unity. The image of the land in Resurrection ties together thematic and ideological strata of the novel that manifest its epic features. I argue that although Tolstoy abandoned his initial intention to make the acute social and political landrelated issue the center of his work, the motif nevertheless remains relevant. The image of the land is ciphered in the description of the severity of prisoners' life and Nekhlyudov's attempts to help the prisoners. Moreover, it is closely connected with all spheres of Russian life, it is a marker of Nekhlyudov's spiritual growth that allows not only place the character's "resurrection" within specific realities of historical time, but also presents it in the traditions of Christian anthropology. The image of the land allots the novel with trans-historical meaning and contributes to the implementation of the religious consciousness in Tolstoy's work.

Keywords: Tolstoy, epic novel, epic, image of the earth, land question, state, stages of spiritual growth, Christian anthropology.

Information about the author: Valeria G. Andreeva, DSc in Philology, Leading Research Fellow, A.M. Gorky Institute of World Literature of the Russian Academy of Sciences, Povarskaya 25 a, I2I069 Moscow, Russia; Professor of Philology Department, Kostroma State University, Dzerzhinsky St. I7, I56005 Kostroma, Russia. ORCID ID: https://orcid.org/oooo-0002-4558-3153

E-mail: lanfra87@mail.ru

For citation: Andreeva V.G. The Image of the Land and Its Functions in Tolstoy's Novel Resurrection. Studia Litterarum, 2020, vol. 5, no 3, pp. 236-25I. (In Russ.) DOI: https://doi.org/I0.22455/2500-4247-2020-5-3-236-25I 
Роман Л.Н. Толстого «Воскресение», вышедший в последний год XIX в., обладает эпической широтой, но при этом удивительной емкостью. В художественном мире произведения множество антитез, передающих противоречия русской действительности, немало предчувствий автора и предостережений, обращенных к людям, забывшим истинные ценности жизни.

В «Воскресении» поднимаются острые социальные и политические проблемы, изображаются конкретные реалии русской жизни рубежа XIX$\mathrm{XX}$ вв., однако произведение имеет надэпохальное значение, оно трансисторично. Прежде чем обратиться к образу земли в романе, оговоримся о его жанровом своеобразии, поскольку оно во многом и организуется, и поддерживается за счет стройной системы компонентов изобразительности художественного мира.

В последнем романе Толстой на новом материале воплотил многие предшествующие свои открытия и в первую очередь найденную им эпическую широту повествования. Как справедливо отмечают исследователи, эпическое мироощущение Толстого проявилось уже в Севастопольских рассказах, рассматривая которые Е.А. Масолова выстраивает диалектику трех эпох: «Севастопольский цикл Л.Н. Толстого, на наш взгляд, представляет своеобразную триаду, где эпическое объединяющее начало первого очерка (этап “утверждения”) сменяется трагическим несоответствием эпическим образцам во втором очерке (этап “отрицания”); в “Севастополе в августе” показано становление человека, приходящего к эпическому мироотношению (этап “синтеза”)» [7, с. I43]. Мерилом и важнейшим показателем эпического начала в данном случае выступает особая национальная сплочен- 
ность, народное единство, создаваемое на основе противостояния врагу во время защиты своей земли.

Фактически это же эпическое понимание и измерение жизни воплощается в «Войне и мире», где присутствуют собственно эпопейные признаки. Несмотря на то что роман «Воскресение» написан на материале современной автору действительности, в этом произведении нет внешней угрозы, перед которой оказалась бы Россия (как во время Крымской войны в Севастопольских рассказах и тем более во время русско-французской войны в «Войне и мире»), Толстой подводит читателя к проблеме нарастания в России страшного кризиса, к проблеме сохранения национальной целостности и выживания народа.

По словам Г.Д. Гачева, чтобы состоялось эпическое произведение, «“искусственное общежитие должно встать перед одной ситуацией - смерти (войны не шуточной, а той, где речь идет о жизни и смерти)” и здесь, на ее рубеже, ощутить ее полную зависимость от естественного течения жизни и естественного общежития» [2, с. 83]. Поразительно, но в «Воскресении», на фоне относительно мирного течения жизни, мы видим страну именно на «грани жизни и смерти». И здесь речь идет о двух взаимосвязанных моментах: в первую очередь о судьбе народа, находящегося в большинстве своем в крайней бедности и нищете. Уместно тут вспомнить диалог двух мальчиков из деревни в имении Нехлюдова Паново, рассуждающих о том, кто самый бедный в деревне:

- Кто бедный? Михайла бедный, Семен Макаров, еще Марфа дюже бедная.

- А Анисья - та еще бедней. У Анисьи и коровы нет - побираются, - сказал маленький Федька.

- У ней коровы нет, да зато их всего трое, а Марфа сама пята, - возражал старший мальчик.

- Все-таки та вдова, - отстаивал розовый мальчик Анисью.

[IO, T. 32, c. 212]

Обратим внимание на этот подробный диалог: бедных очень много, и обнищание народа настолько велико, что мальчики даже не могут решить, кто беднее. И фигуры встречающихся Нехлюдову в деревне крестьян и их 
детей еще раз доказывают справедливость слов ребят: «И та худая женщина, которая легко держала на руке бескровного ребеночка в скуфеечке из лоскутиков. Ребенок этот не переставая странно улыбался всем своим старческим личиком и все шевелил напряженно искривленными большими пальцами. Нехлюдов знал, что это была улыбка страдания» [Іо, т. 32, с. 2І6]. Обобщая свои наблюдения, Нехлюдов делает вывод о вымирании народа: «Народ вымирает, привык к своему вымиранию, среди него образовались приемы жизни, свойственные вымиранию...» [Іо, т. 32, с. 2І7].

Во-вторых, положение страны в состоянии перелома передает глубочайшая нравственная и духовная деградация, напрямую связанная с порабощением народа. Обличая чиновников разных уровней, Толстой демонстрирует в романе антигуманную, противоестественную природу власти. Аналитическое изучение образов судей, прокуроров, смотрителей, военных всех уровней и званий приводит читателя к выводу о том, что, по Толстому, практически невозможно встретить порядочного человека во власти, поскольку сама власть или ломает человека, или заставляет его заглушать в себе все зовы совести. Читатель романа, наблюдающий за тщетными попытками Нехлюдова способствовать быстрому пересмотру дела Масловой, подводится к мысли о кризисе существующей государственности.

В воспоминаниях Н.Н. Гусева есть интересный эпизод, очень хорошо передающий отношение писателя к большинству описанных им чиновников высокого ранга: «За вечерним чаем М.А. Стахович вспоминал о том, как Лев Николаевич посетил орловскую тюрьму. Это было в то время, когда он писал “Воскресение”. <...> "Вы виделись тогда с орловским губернатором, сказал М.А. Стахович, - которого после изобразили в “Воскресении” под именем Масленникова”. “Да неужели я такую гадость сделал?” - смеясь, спросил Лев Николаевич» [5, с. 88].

Спасение человечества Толстой видел не в изменении государственного строя, не в реформах, но исключительно в нравственной работе каждого человека, в постепенном приближении к вере, Божественным заповедям, осознанию ценности любовного отношения к людям. По сути дела, писатель говорил о необходимости трансформации государственности в ее современном для него виде, т. е. речь идет о собственно эпопейном переходе: «Эпос носит на себе печать перехода от непосредственного, народного общежития “миром” к собственно общественной жизни в государстве. 
С другой стороны, через форму эпоса, эпопеи всегда можно совершать обратный переход: от официально-государственного мировоззрения - к народному; можно судить жизнь и отношения людей в обществе с точки зрения народного общежития “миром”» [2, с. 82].

В романе «Воскресение» важно понять представленное соотношение личного и общего: указанный выше переход к жизни большим миром, к настоящим ценностям должен, по мнению писателя, совершить каждый человек. Под большим миром Толстой понимает не крестьянскую общину, но весь русский народ, живущий честной, простой, трудовой жизнью. И контрастное сопоставление Нехлюдова передает попытку героя выйти к народному мировоззрению: «“Да, совсем новый, другой, новый мир”, - думал Нехлюдов, глядя на эти сухие, мускулистые члены, грубые домодельные одежды и загорелые, ласковые и измученные лица и чувствуя себя со всех сторон окруженным совсем новыми людьми с их серьезными интересами, радостями и страданиями настоящей трудовой и человеческой жизни. “Вот он, le vrai grand monde (подлинно большой свет)" - думал Нехлюдов, вспоминая фразу, сказанную князем Корчагиным, и весь этот праздный, роскошный мир Корчагиных с их ничтожными, жалкими интересами» [Іо, т. 32, с. 36I].

Одним из ключевых в романе «Воскресение» является образ земли. Он включен в стройную систему толстовских антитез, поддерживает и во многом организует сущность эпического романа - вершинной формы жанра в русской литературе второй половины XIX в. В художественном мире произведения важно не столько то, что лексема «земля» представлена в различных смыслах, сколько то, что указанный образ организует определенные тематические и идейные пласты, напрямую связанные с реализацией эпопейных признаков. Образ земли обретает в романе как изобразительные, так и выразительные задачи: последние понимаются Е.Б. Тагером как «потребность в освоении действительности в формах емких, экономных, подчеркивающих авторское осмысление глубинной сути явления, насыщенных действенной авторской оценкой» [9, с. 323].

В художественном мире эпического романа «Воскресение», как и в романе-эпопее «Война и мир», русская земля нуждается в защите. Но если в «Войне и мире» речь идет о спасении русской земли от французов, то в «Воскресении» - о защите земли от людей, не осознающих ее ценности, 
спекулирующих ею. На вопрос Нехлюдова о найме земли извозчик, подвозивший его до тюрьмы, отмечает: «Где нынче нанять? Господишки, какие были, размотали свою. Купцы всю к рукам прибрали. У них не укупишь, сами работают. У нас француз владеет, у прежнего барина купил. Не сдает да и шабаш» [Іо, т. 32, с. 270].

Земельный вопрос Толстой считал одним из основных, очень переживал по поводу тяжести положения народа, не имеющего достаточных участков для ведения хозяйства. Толстой активно распространял учение Генри Джорджа, считая его самым справедливым (американский политэконом считал, что причины обнищания народа заключаются в возрастании земельной ренты). Во время работы над «Воскресением» писатель в течение определенного периода планировал сделать земельный вопрос центральным в романе, однако постепенно он отошел на второй план, уступил место изображению жизни заключенных и ссыльных, этапов духовного возрождения главных героев, мытарств Нехлюдова, пытающегося добиться повторного рассмотрения дела Катюши в Сенате и различных послаблений для других заключенных. Нельзя согласиться с В.А. Тунимановым в том, что земельный вопрос был вытеснен из центральных тем и проблем романа. «Попытка поставить земельный вопрос в центре романа оказалась неудачной - Генри Джордж и единый налог не исчезли совсем, слишком дороги были эти идеи Толстому, однако переместились на обочину повествования», - отмечает В.А. Туниманов [6, с. 554-555]. Слишком малозначительной посчитал ученый роль земельного вопроса. На самом деле этот вопрос не ушел на обочину романа, а оказался лишь немного заслоненным внешними ироническими и сатирическими изображениями высшего света. При внимательном прочтении становится понятно, что стадии процесса воскресения Нехлюдова коренным образом связаны с его отношением к земле. Не случайно в ответе на письмо некоему П. Полилову (за этой фамилией скрывалась Т.Л. Толстая) писатель подчеркнул глубинную связь земельного вопроса с нравственной жизнью человека: «Ваша статья с письмом ко мне доставила мне большую радость. Я давно уже перестал, да и никогда не интересовался политическими вопросами, но вопрос о земле, то есть земельном рабстве, хотя и считается вопросом политическим, есть, как Вы совершенно верно говорите, вопрос нравственный, вопрос нарушения самых первобытных требований нравственности, и потому вопрос этот не только занимает, но мучает меня...» [8, с. 362]. 
Как другие дорогие для автора герои его более ранних повестей и романов, Дмитрий Нехлюдов проходит несколько этапов. Герой сравнивает себя в настоящем, вспоминает свою молодость и наступившее потом помрачение, приближается к выводу о необходимости перемен. Но к финальному открытию и осмыслению Божественных заповедей он добирается через сомнения. Конечно, духовное восхождение Нехлюдова констатирует целая гамма перемен во внешнем поведении героя и в его ощущении себя, понимании мира, но его отношение к земле является наиболее показательным.

По нашему мнению, этот идейный ход был продуман и выверен автором, он во многом позволил Толстому вписать воскресение Нехлюдова не в конкретные реалии времени, представить в традициях не исторической, но христианской антропологии. Как справедливо отметила Н.Ю. Алексеева, «христианская антропология мыслит человека вне времени, в том смысле, что время, согласно ей, не оказывает решающего воздействия на природу человека, человек первых веков по своей сущности неотличим от человека последних [І, с. І2-І13].

Русская природа и земля как источник жизни в романе сакрализованы, образ пробуждающейся и расцветающей земли - символ победы над смертью - представлен в художественном мире романа несколько раз, причем всегда в паре с антитезами. Начало романа «Воскресение» стало почти хрестоматийным, однако важно указать, что развернутое описание весны открывается образом земли, подготавливающим, обусловливающим это пробуждение: «Как ни старались люди, собравшись в одно небольшое место несколько сот тысяч, изуродовать ту землю, на которой они жались, как ни забивали камнями землю, чтобы ничего не росло на ней, как ни счищали всякую пробивающуюся травку, как ни дымили каменным углем и нефтью, как ни обрезывали деревья и ни выгоняли всех животных и птиц, - весна была весною даже и в городе» (курсив мой. - B.A.) [Іо, т. 32, с. 3]. В художественном мире романа присутствует еще одно, рифмующееся с этим описание. В начале произведения указанный отрывок представлен всезнающим повествователем, а в финале второй части к этим же мыслям приходит прозревающий Нехлюдов. Его показательное сравнение земли и ее назначения с чувствами людей предшествует осознанию героем ценности трудового народного мира. Интересна и значима композиция эпизода: сначала автор рассуждает о служащих, объединяя их словами «все эти люди», затем следует великолепное описание 
жаждущей дождя земли, рождающей урожай: «Он перешел на другую сторону и, вдыхая влажную свежесть и хлебный запах давно ждавшей дождя земли, смотрел на мимо бегущие сады, леса, желтеющие поля ржи, зеленые еще полосы овса и черные борозды темно-зеленого цветущего картофеля» [Іо, т. 32, с. 350], а потом Нехлюдов размышляет о свойстве земли рождать урожай и способности человека любить других: «Все эти люди, очевидно, были неуязвимы, непромокаемы для самого простого чувства сострадания только потому, что они служили. Они, как служащие, были непроницаемы для чувства человеколюбия, как эта мощеная земля для дождя, - думал Нехлюдов, глядя на мощенный разноцветными камнями скат выемки, по которому дождевая вода не впитывалась в землю, а сочилась ручейками. - Может быть, и нужно укладывать камнями выемки, но грустно смотреть на эту лишенную растительности землю, которая бы могла родить хлеб, траву, кусты, деревья, как те, которые виднеются вверху выемки. То же самое и с людьми, - думал Нехлюдов, - может быть, и нужны эти губернаторы, смотрители, городовые, но ужасно видеть людей, лишенных главного человеческого свойства - любви и жалости друг к другу» [Іо, т. 32, с. 351].

Земля в романе представлена одной из величайших ценностей: но отношение к ней кардинально различается: земля как материальное благо, источник дохода свыше жизненных потребностей становится искушением, земля как кормилица, как источник и основа всего живого почитается. Эти две стороны отношения к земле в произведениях Л.Н. Толстого и М.М. Пришвина очень хорошо передал И.С. Урюпин: «Земля <...> - не просто источник существования, а сама основа жизни, ее физическое и духовное первоначало, сакральная природа которого хорошо осознается человеком, чувствующим неодолимую “власть земли”. В русском народном сознании еще со времен язычества утвердилось двойственное представление о земле и как о подательнице всяких благ (земля-кормилица), и как о необоримой силе, порабощающей человека, парализующей его волю, крепко сжимающей в объятьях и затягивающей в свои недра (земля-поглотительница). Отсюда в русском народе сформировалось специфическое отношение к земле, которое можно было бы определить одновременно и как почти религиозное, исполненное страха и трепета, преклонения, и как сугубо прагматическое, основанное на стремлении получить от нее максимум материальной выгоды» [ı, с. 87-88]. 
Дочь Толстого, Татьяна Львовна, отметила особую привязанность отца к земледельческому труду: «Любовь отца к земле и уважение его к земельному труду были не только принципиальными, но и органическими. До его так называемого переворота, или перелома, отец страстно занимался хозяйством, совершенствуя все его отрасли, насколько это было в его силах. С крестьянским земледельческим трудом он всегда близко соприкасался и часто в нем участвовал» [8, с. 35I]. Множество эпизодов в произведениях Толстого показывают его уважение к крестьянскому труду: вспомним хотя бы косьбу Константина Левина с мужиками. Писатель считал, что труд на земле - это естественное дело и потребность человека. $\mathrm{B}$ «Воскресении» читатель также убеждается, что работа на земле облагораживает душу человека, позволяет ему понять себя и окружающих. Примечателен эпизод с изменением Федосьи, попытавшейся отравить нелюбимого мужа, а потом, во время совместной работы на земле, осознавшей свою огромную любовь к нему.

Земля для большинства господ и почти для всех служащих, как отмечает Толстой, это состояние, источник дохода, получаемого в результате обработки и использования этой земли другими: «А между тем ясно совершенно, что дети и старые люди мрут оттого, что у них нет молока, а нет молока потому, что нет земли, чтобы пасти скотину и собирать хлеб и сено. Совершенно ясно, что все бедствие народа или, по крайней мере, главная, ближайшая причина бедствия народа в том, что земля, которая кормит его, не в его руках, а в руках людей, которые, пользуясь этим правом на землю, живут трудами этого народа. Земля же, которая так необходима ему, что люди мрут от отсутствия ее, обрабатывается этими же доведенными до крайней нужды людьми для того, чтобы хлеб с нее продавался за границу и владельцы земли могли бы покупать себе шляпы, трости, коляски, бронзы и т. п.» [Іо, т. 32, с. 218].

В «Воскресении» реализован также мотив искушения землей, связанный с переживаниями Нехлюдова. В начале романа, получив письмо управляющего, который предлагает купить дополнительный инвентарь и всю отдаваемую крестьянам землю обрабатывать самим с помощью наемных рабочих, Нехлюдов вспоминает свои юношеские идеалы и планы, увлечение работами Герберта Спенсера и убежденность в том, что земля не может быть предметом частной собственности. Герой понимает, как далеки 
теперь для него, отяжелевшего человека, привыкшего к роскошной жизни, те высокие убеждения юности. Необходимость следования за Катюшей в Сибирь побуждает Нехлюдова вернуться к вопросу о земле. Герой осознает, что не должен владеть землею, он приезжает в свое большое имение Кузьминское с планом передачи земли мужикам в наем по невысокой цене. Но тут его ожидает искушение: Нехлюдов жалеет землю. Сомнения мужиков в честности и искренности барина также останавливают героя: Нехлюдов еще не готов отдать землю сознательно, первый порыв выглядит с его стороны как желание решить вопрос, как-то завершить это дело. Он пока не понимает глубинного смысла фраз мужиков о том, что они кормятся землей. Нехлюдов совершает прогулку по деревне, заходит в гости в мужицкую избу и разговаривает с хозяевами:

- А своего разве недостает?

- Своего?! - с презрительной усмешкой сказал старик. - У меня земли на три души, а нынче всего восемь копен собрали, - до Рождества не хватило.

- Да как же вы делаете?

- Так и делаем; вот одного в работники отдал, да у вашей милости деньжонок взял. Еще до заговенья всё забрали, а подати не плачены.

- А сколько податей?

- Да с моего двора рублей семнадцать в треть сходит. Ох, не дай Бог, житье, и сам не знаешь, как оборачиваешься!

[10, т. 32, с. 210]

Во втором, меньшем имении Паново Нехлюдов наблюдает еще большую бедность и запустение. В Кузьминском ощущение нужности многих дорогих для него вещей, боязнь того, что деньги могут пригодиться на будущее, удерживали героя, однако в Паново Нехлюдов освобождается от странных воспоминаний и жалости. По словам дочери Толстого, эпизод с передачей земли крестьянам Нехлюдовым в имении Паново был создан Толстым с опорой на личный опыт: вместе с юной Татьяной Львовной Толстой озвучивал предложение о передаче земли крестьянам деревни Овсянниково. А.В. Гулин отметил, что «лекарством от цивилизации» для толстовских героев обычно становится простое и сильное, часто прямо фи- 
зическое потрясение [4, c. I74]. Именно такое сильное физическое потрясение Нехлюдов переживает в своих имениях, видя тяготы жизни крестьян и узнавая о смерти собственного ребенка от Катюши, умершего по пути в воспитательный дом.

Но, в отличие от Нехлюдова, большинство его бывших друзей и знакомых из высшего света не тяготятся властью земли и обладанием капиталами. Самым близким людям в высшем свете - сестре Наталье, ее мужу, тетушке - графине Чарской - Нехлюдов пытается объяснить странное и неправильное положение дел. Графине Чарской он говорит о страшной роскоши, в которой живет она сама и высший свет. Сестре и ее мужу, Игнатию Никифоровичу, Нехлюдов пытается объяснить свое желание отдать землю крестьянам. Но и сестра, и тем более ее муж не понимают Нехлюдова, не чувствуют того, что им движет. Игнатий Никифорович пытается увидеть в поступке Нехлюдова хвастовство, желание вызвать о себе разговоры, он относится к действиям Нехлюдова с осуждением, видя в них подрыв существующего порядка дел. Не случайно Нехлюдов констатирует, что сестра, вышедшая замуж, стала для него чужим человеком. Игнатий Никифорович выражает в романе точку зрения, полностью противоположную мнению Нехлюдова и позиции автора. «Я полагаю, что все мы, поставленные в известное положение, должны нести те обязанности, которые вытекают из этого положения, должны поддерживать те условия быта, в которых мы родились и унаследовали от наших предков и которые должны передать нашим потомкам», - заявляет Игнатий Никифорович, отстаивая право владения землей [Іо, т. 32, с. 32г]. В данном случае отношение к земле позволяет писателю дать второстепенным героям однозначную характеристику, подчеркнуть типичность позиции, существующей в обществе, и наглядно продемонстрировать жестокость и равнодушие, с которыми сталкивается Нехлюдов. Уместно тут проиллюстрировать мнение самого писателя по поводу вопроса наследования земли. «Как странно и тяжело на меня действует вид детей моих, владеющих землей и заставляющих работать народ. Как угрызение совести. И это не рассуждение, а чувство, и очень сильное», отметил Толстой в дневнике за І2 июня г989 г. [Іо, т. 53, с. І98].

Но в нежелании Нехлюдова делить землю, в отвержении им земельной собственности лежит не политический ход, не экономическая стратегия, а духовное отношение к земле и земледельческому труду. Эпический мас- 
штаб художественного мира романа поддерживается глобальной поездкой Нехлюдова, который фактически пересекает большую часть русской земли, переезжая по делу Масловой и потом вслед за ней от Петербурга и Москвы до сибирского города. Просторы России воскрешают в памяти читателя не только мысль о необходимости единства русской земли, ярко выраженную еще в древнерусской литературе, но и глубинную идею богоданности земли и ее благ человечеству. Уместно в данном случае вспомнить фигуру старика на пароме, свидетелем рассказа которого становится Нехлюдов. Разумеется, точка зрения старика-сектанта на жизнь и людей отличается от авторской, однако Толстой позволяет этому страннику произнести важнейшие слова: «Нет, говорю, у меня ни отца, ни матери, окроме Бога и земли. Бог - отец, земля - мать» [Іо, т. 32, с. 4I9].

Вызывает интерес еще один эпизод, не получивший реализации в окончательном тексте романа, но имеющийся в черновых материалах. В планах Толстого, от которых писатель потом отказался, было описание женитьбы Нехлюдова на Катюше, их жизни в России и за рубежом. Нас в данном случае интересуют два момента. Во-первых, несколько ироническое описание хозяйства Нехлюдова, не приспособленного к работе на земле: «Планы Нехлюдова далеко не осуществились. Устройство сада и огорода, в котором бы он сам работал, не удалось ему. Не удалось потому, что часть его времени была занята перепиской с проповедниками идеи освобождения от земельного рабства как в Европе, так и в Америке, другая же часть - сочинением книги о земельной собственности и кроме того обучением детей, которые приходили к нему. <...> Так что он должен был добывать себе средства жизни, что он и делал, садом и огородом и статьями в русских и заграничных изданиях [го, т. 33, с. 93]. Во-вторых, мотив изгнания (от которого Толстой вынужден быть отказаться за ненадобностью, так как сюжет получил иное развитие): «Скоро, однако, деятельность его показалась правительству столь вредной, что его решили сослать в Амурскую область. Лишенный средств существования и угрожаемый еще худшей ссылкой, Нехлюдов воспользовался представившимся случаем и бежал с женою за границу. Теперь он живет в Лондоне с женою, прошедшее которой никто не знает, и, пользуясь уважением своих единомышленников, усердно работает в деле уяснения и распространения идеи единой подати» [Іо, т. 33, с. 94]. 
Не исключено, что подобный ход мог быть продуман Толстым в традициях античного мотива изгнания за пределы Родины, ставшего «важнейшим идентификационным жестом, который вписывается в риторику римской государственности, поскольку политический изгнанник отторгается не только от территории, но и от общего проекта служения Родине» [3, с. 53]. Отказ писателя от такого поворота дел был, скорее всего, связан не только с искусственностью брака Нехлюдова на Катюше, но и с пересмотром понятия государственность. В художественном мире романа любовь к земле имеет особое понимание: Толстым актуализируется и утверждается не служение гражданина государству и власти, но служение земле, помощь другим людям, забота о ближних.

Духовный рост Нехлюдова сопровождается изменением отношения к действительности. Дважды в романе Толстой акцентирует внимание читателя на этом состоянии героя, используя одно и то же сравнение: «Он испытывал неперестающую радость освобождения и чувство новизны, подобное тому, которое должен испытывать путешественник, открывая новые земли» [Іо, т. 32, с. 233]; «И он испытал чувство радости путешественника, открывшего новый, неизведанный и прекрасный мир» [г, т. 32, с. 36I]. Примечательны тут понятия «новые земли» и «новый мир»: по нашему мнению, Толстой имеет в виду не только новое мировидение героя, писатель максимально расширяет границы эпического романа - речь идет о своеобразном космополитизме, о непреходящей ценности человеческой души, для которой не существует границ и условностей.

Итак, многочисленные реализации образа земли в романе Толстого «Воскресение» позволяют говорить о его значимой роли не только в выражении идейно-мировоззренческой позиции автора, но и в создании и поддержании особой эпической широты произведения. Образ земли в романе многозначен, вступает в различные смысловые отношения с другими ключевыми компонентами изобразительности, способствуя организации таких свойств и признаков эпического романа, как особая целостность и тотальность художественного мира, изображение народной жизни, наличие религиозного сознания, объективность повествования, широкий охват событий, преодоление столкновения между личностью и обществом, масштабность конфликтов, наличие точек зрения и голосов героев, повторяемость событий, свойственная для прецедентной картины мира. 


\section{Список литературы}

I Алексеева Н.Ю. Некоторые замечания по поводу работы над историей русской литературы // Русская литература. 2018. № 4. С. 7-I4.

DOI: I0.31860/0I3I-6095-2018-4-7-I4

2 Гачев Г.Д. Содержательность художественных форм. М.: Просвещение, I968. $302 \mathrm{c.}$

3 Гузенина С.В. Образ родной земли как духовно-нравственная ценность древних цивилизаций // Наука и образование. 2019. № 2. С. 53.

4 Гулин А.В. Богучаровский «бунт» в «Войне и мире» Л.Н. Толстого: источники, философия, поэтика // Studia Litterarum. 2020. Т. 5, № I. С. I62-I77.

DOI: I0.22455/2500-4247-2020-5-I-I62-I77

5 Гусев Н.Н. Два года с Л.Н. Толстым. Воспоминания и дневник бывшего секретаря Л.Н. Толстого. М.: Худож. лит., І973. 464 с.

6 Зверев А.М., Туниманов В.А. Лев Толстой. М.: Молодая гвардия, 2007. 782 с.

7 Масолова Е.А. Становление эпического в Севастопольских рассказах Л.Н. Толстого // Ученые записки Казанского университета. Серия: Гуманитарные науки. 20I6. T. I58, № I. C. I33-I45.

8 Сухотина Т.А. Воспоминания. М.: Худож. лит., 1976. 54I с.

9 Тагер Е.Б. Избранные работы о литературе. М.: Сов. писатель, І988. 506 с.

го Толстой Л.Н. Полн. собр. соч.: в 90 т. М.: Худож. лит., І928-1958.

II Урюпин И.С. Евразийский контекст мифологемы искушения землей в прозе Л.Н. Толстого, М.М. Пришвина, А.И. Солженицына // Эпическая традиция в русской литературе XX-XXI веков: Материалы XXIII Шешуковских чтений. 2019. C. $85^{-95}$. 


\section{References}

I Alekseeva N.Iu. Nekotorye zamechaniia po povodu raboty nad istoriei russkoi literatury [Some comments on the work on the history of Russian literature]. Russkaia literatura, 20I8, no 4, pp. 7-I4. DOI: I0.31860/OI3I-6095-20I8-4-7-I4 (In Russ.)

2 Gachev G.D. Soderzhatel'nost' khudozhestvennykh form [The content of art forms]. Moscow, Prosveshchenie Publ., I968. 302 p. (In Russ.)

3 Guzenina S.V. Obraz rodnoi zemli kak dukhovno-nravstvennaia tsennost' drevnikh tsivilizatsii [The image of the native land as the spiritual and moral value of ancient civilizations]. Nauka i obrazovanie, 20I9, no 2, p. 53. (In Russ.)

4 Gulin A.V. Bogucharovskii "bunt” v "Voine i mire” L.N. Tolstogo: istochniki, filosofiia, poetika [The "Rebellion” in Bogucharovo in Leo Tolstoy's War And Peace: sources, philosophy, and poetics]. Studia Litterarum, 2020, vol. 5, no I, pp. I62-I77. DOI: I0.22455/2500-4247-2020-5-I-I62-I77. (In Russ.)

5 Gusev N.N. Dva goda s.N. Tolstym. Vospominaniia i dnevnik byvshego sekretaria L.N. Tolstogo [Two years with L.N. Thick. Memoirs and diary of the former secretary L.N. Tolstoy]. Moscow, Khudozhestvennaia literatura Publ., I973. 464 p. (In Russ.)

6 Zverev A.M., Tunimanov V.A. Lev Tolstoi [Lev Tolstoy]. Moscow, Molodaia gvardiia Publ., 2007. 782 p. (In Russ.)

7 Masolova E.A. Stanovlenie epicheskogo v Sevastopol'skikh rasskazakh L.N. Tolstogo [The development of the epic in Sevastopol Tales by Leo Tolstoy]. Uchenye zapiski Kazanskogo universiteta. Seriia: Gumanitarnye nauki, 20I6, vol. I58, no I, pp. I33-I45. (In Russ.)

8 Sukhotina T.A. Vospominaniia [Memories]. Moscow, Khudozhestvennaia literatura Publ., I976. 54I p. (In Russ.)

9 Tager E.B. Izbrannye raboty o literature [Selected works on literature]. Moscow, Sovetskii pisatel' Publ., I988. 506 p. (In Russ.)

IO Tolstoi L.N. Polnoe sobranie sochinenii: $v$ go $t$. [Complete works: in 90 vols.]. Moscow, Khudozhestvennaia literatura Publ., I928-I958. (In Russ.)

II Uriupin I.S. Evraziiskii kontekst mifologemy iskusheniia zemlei v proze L.N. Tolstogo, M.M. Prishvina, A.I. Solzhenitsyna [The Eurasian context of the mythology of temptation by the land in the fiction by L.N. Tolstoy, M.M. Prishvin, A.I. Solzhenitsyn]. In: Epicheskaia traditsiia v russkoi literature XX-XXI vekov. Materialy XXIII Sheshukovskikh chtenii [Epic tradition in Russian literature of the $2 \mathrm{O}^{\text {th }}-2 \mathrm{I}^{\text {th }}$ centuries: Materials of the XXIII Sheshukov readings], 20I9, pp. 85-95. (In Russ.) 